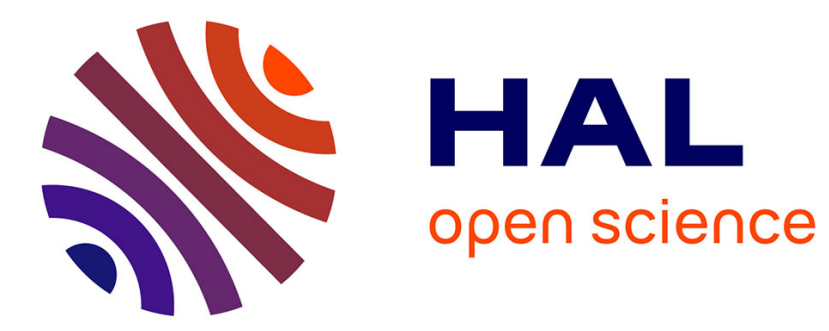

\title{
Influence of edge conditions on material ejection from periodic grooves in laser shock-loaded tin
}

\author{
T. de Resseguier, C. Roland, G. Prudhomme, E. Lescoute, D. Loison, P.
} Mercier

\section{- To cite this version:}

T. de Resseguier, C. Roland, G. Prudhomme, E. Lescoute, D. Loison, et al.. Influence of edge conditions on material ejection from periodic grooves in laser shock-loaded tin. Journal of Applied Physics, 2016, 119 (18), 10.1063/1.4949483 . hal-01324409

\section{HAL Id: hal-01324409 \\ https://hal.science/hal-01324409}

Submitted on 13 Jul 2018

HAL is a multi-disciplinary open access archive for the deposit and dissemination of scientific research documents, whether they are published or not. The documents may come from teaching and research institutions in France or abroad, or from public or private research centers.
L'archive ouverte pluridisciplinaire HAL, est destinée au dépôt et à la diffusion de documents scientifiques de niveau recherche, publiés ou non, émanant des établissements d'enseignement et de recherche français ou étrangers, des laboratoires publics ou privés. 


\title{
Influence of edge conditions on material ejection from periodic grooves in laser shock-loaded tin
}

T. de Rességuier ${ }^{1}$, C. Roland ${ }^{1}$, G. Prudhomme ${ }^{2}$, E. Lescoute ${ }^{2}$, D. Loison ${ }^{3}$, P. Mercier ${ }^{2}$

${ }^{1}$ Institut PPRIME, UPR 3346, CNRS, ENSMA, Université de Poitiers, 1 ave. Clément Ader, 86961 Futuroscope Cedex, France

${ }^{2}$ CEA, DAM, DIF, 91297 Arpajon, France

${ }^{3}$ Institut de Physique de Rennes, CNRS, Université de Rennes 1, 35042 Rennes, France

\begin{abstract}
In a material subjected to high dynamic compression, the breakout of a shock wave at a rough free surface can lead to the ejection of high velocity debris. Anticipating the ballistic properties of such debris is a key safety issue in many applications involving shock loading, including pyrotechnics and inertial confinement fusion experiments. In this paper, we use laser driven shocks to investigate particle ejection from calibrated grooves of micrometric dimensions and approximately sinusoidal profile in tin samples, with various boundary conditions at the groove edges, including single groove and periodic patterns. Fast transverse shadowgraphy provides ejection velocities after shock breakout. They are found to depend not only on the groove depth and wavelength, as predicted theoretically and already observed in the past, but also, unexpectedly, on the edge conditions, with a jet tip velocity significantly lower in the case of a single groove than behind a periodic pattern.
\end{abstract}

PACS 62.50.Ef - High pressure and shock wave effects in solids and liquids

PACS 47.40.Nm - Shock-wave interactions and shock effects

PACS 83.60.Wc - Flow instabilities 


\section{Introduction}

When a shock wave propagating in a material subjected to dynamic compression breaks out at a free surface, it is reflected into a rarefaction wave and the surface undergoes a sharp acceleration. If the free surface presents geometrical defects such as scratches, pits or grooves, high velocity debris can be ejected from these defects, ahead of the main surface. Distinct defects may generate thin jets (which is sometimes referred to as microjetting) while a global roughness can lead to the expansion of a cloud of fine particles (sometimes called material ejection). Because this cloud may disrupt surface diagnostics used in shock physics (velocity interferometry, pyrometry, reflectivity) and because the impact of the ejecta can cause severe damage to nearby equipment in practical, engineering applications, this process has been widely studied both theoretically and experimentally under impact or explosive loading [1-13]. In a recent paper, we used laser driven shock loading to investigate microjetting from triangular, individual grooves of micrometric dimensions in several metals, both below and above shockinduced melting [14]. In particular, transverse shadowgraphy allowed measuring jet tip velocities over a range of experimental conditions. Then the question arose whether such velocities might be different in the case of periodic grooves, more representative of machined or rolled surfaces of practical interest, i.e. would depend on the boundary conditions at the groove edges. Here, we report further laser shock experiments on tin samples with calibrated grooves of approximately sinusoidal shape and different edge conditions. They show unambiguously that ejection velocity does depend on these edge conditions, with clear differences between single groove and periodic pattern, and even between small and high groove number, unlike what might have been intuitively anticipated. 


\section{Experimental techniques}

Samples were cut from (rolled) tin foils of high purity (99.99\%) and $230 \mu \mathrm{m}$-thickness, with grain size ranging from about $40 \mu \mathrm{m}$ to about $200 \mu \mathrm{m}$. Their surface was polished to mirror-like finish, then straight grooves of approximately sinusoidal profile were engraved by laser ablation. Groove depth $2 h$ (peak to valley) was either $10 \mu \mathrm{m}$ or $18 \mu \mathrm{m}$, controlled by threedimensional optical microscopy (Fig. 1). For both depths, two types of targets were prepared: (i) regular periodic pattern of 17 parallel grooves, with an intergroove wavelength $\lambda=58 \mu \mathrm{m}$ (Fig. 2a), and (ii) three zone-pattern with 3 grooves, 1 groove and 20 grooves, with the same wavelength of $58 \mu \mathrm{m}$ (Fig. 2b). A dimensionless parameter widely used to characterize such periodic geometry and to model subsequent ejection dynamics is the product $k h=2 \pi h / \lambda$. Here, the $k h$ products are 0.5 and 1 for $10 \mu$ m-deep and $18 \mu \mathrm{m}$-deep grooves, respectively.
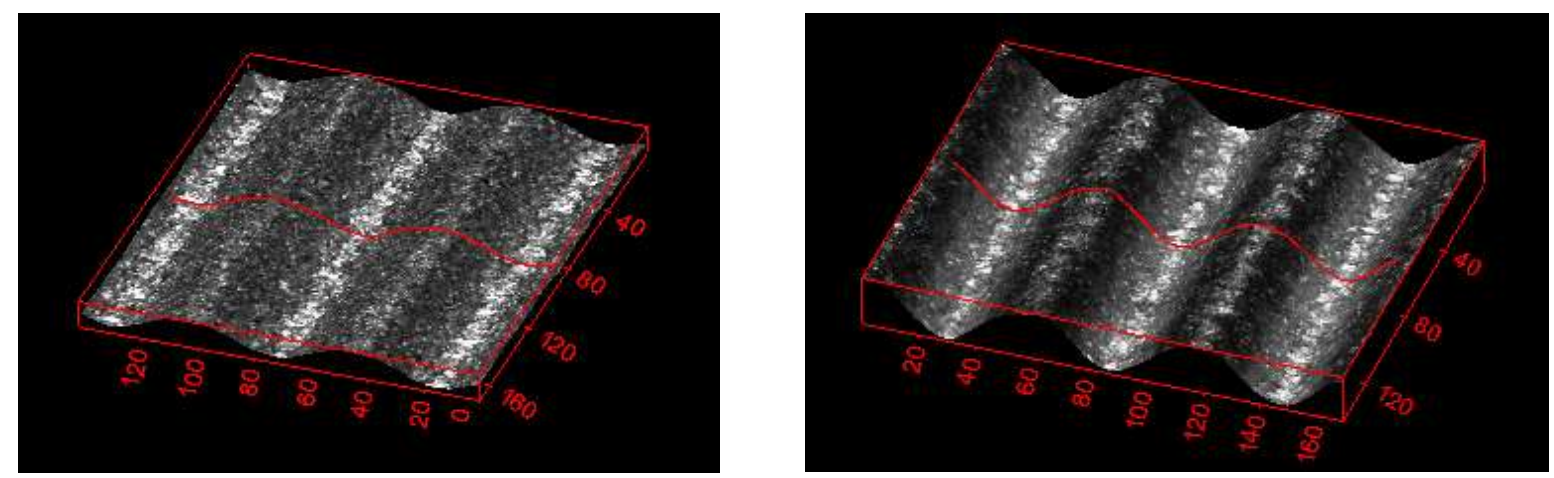

Fig. 1. Three-dimensional reconstruction from optical microscopy of the sinusoidal grooves engraved in the surface of tin samples, with depths of $10 \mu \mathrm{m}$ (left) and $18 \mu \mathrm{m}$ (right). Scales are in $\mu \mathrm{m}$. 
(a)

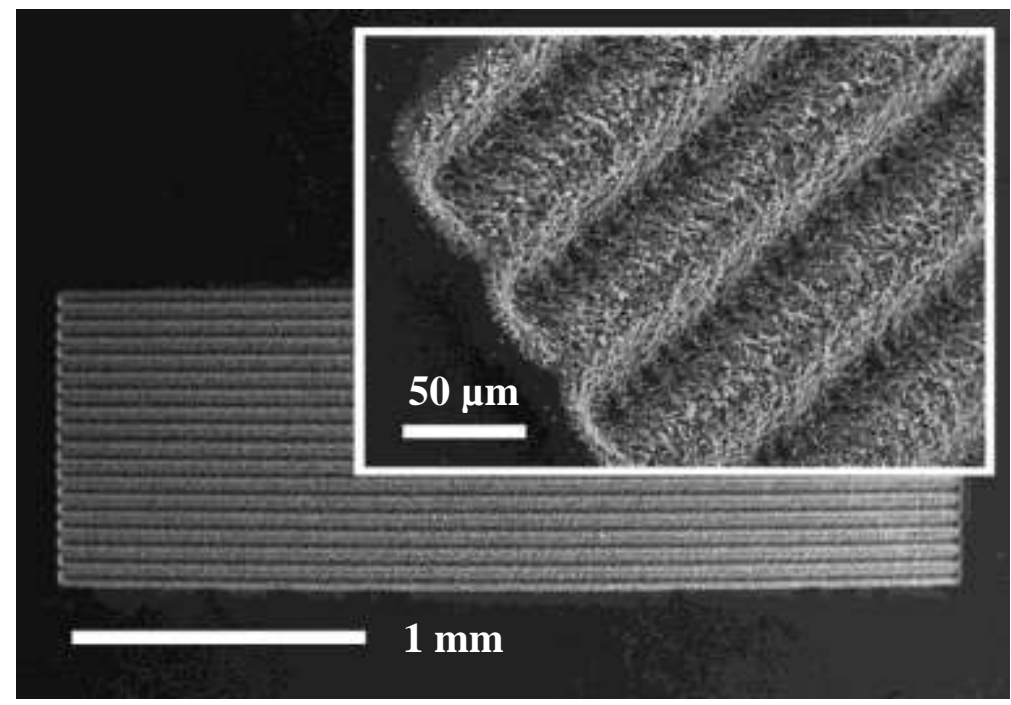

(b)

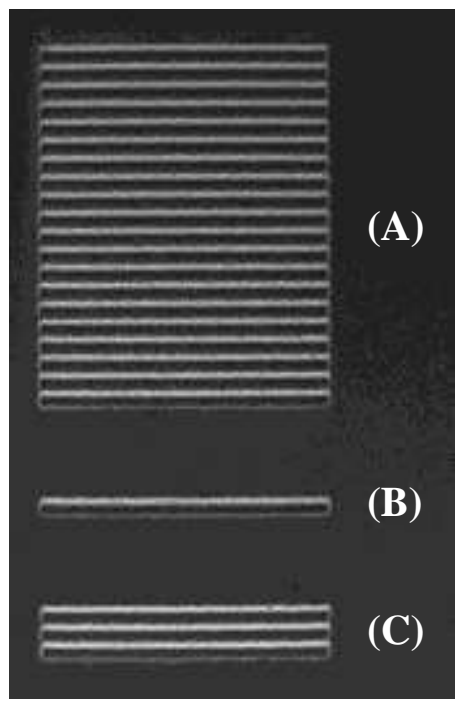

Fig. 2. Scanning electron micrographs of grooved surfaces with a single periodic pattern (a), with a closer view in the inset, and a three zone-pattern (b). Transverse shadowgraphy will be performed along the horizontal direction.

The experiments were performed in the LULI2000 facility of the Laboratoire pour l'Utilisation des Lasers Intenses (LULI, UMR 7605, France). A high power laser pulse of $1.055 \mu \mathrm{m}$-wavelength, 3.4 ns-duration, about $700 \mathrm{~J}$-energy, was focused on a $3.1 \mathrm{~mm}$-diameter spot opposite to the grooved surface (Fig. 3). The resulting intensity was about $2.8 \times 10^{12} \mathrm{~W} / \mathrm{cm}^{2}$. The sample was set in secondary vacuum to avoid laser breakdown in air. A thin layer of material is ablated into a plasma cloud, which expansion toward the laser source drives by reaction a short compressive pulse onto the loaded spot. The amplitude $P_{\text {load, }}$, about $86 \mathrm{GPa}$, and temporal profile of this pulse were inferred at each shot from one-dimensional (1D) computations of laser-matter interaction with the ESTHER hydrocode [15], using the measured profile of laser intensity as input condition, and assuming spatial uniformity of the laser energy distribution over the irradiated spot. The compression front rapidly steepens into a shock wave followed by gradual release, so that the pressure profile becomes roughly triangular (load 
usually referred to as unsupported shock) and peak pressure decays with propagation distance (Fig. 4). Shock breakout pressure $P_{S B}$ after propagation throughout the sample thickness was inferred from the same 1D computations, since radial release waves from the periphery of the loaded spot do not affect wave propagation during this transit. 2D effects inside the grooves, over the last 10 or $18 \mu \mathrm{m}$ before breakout, were neglected. In the shots reported here, $P_{S B}=30.4$ $\mathrm{GPa} \pm 1.1 \mathrm{GPa}$. It is higher than the threshold pressure of about $20 \mathrm{GPa}$ above which tin starts melting upon release $[16,6]$, so that ejection processes upon shock breakout are expected to occur in a mixed solid-liquid state.

Fast transverse shadowgraphy provides sequences of quasi-instantaneous images of material ejection behind the grooved free surface, using two high speed cameras and a wedge beamsplitter as depicted in Fig. 3. Illumination is supplied by a continuous laser of $527 \mathrm{~nm}$ wavelength, divided by a wedge beamsplitter, and four images are recorded by two high speed cameras with different delay times (two images each), which allows to reduce, adapt and control the interframe time at each shot. Short exposure times of $5 \mathrm{~ns}$ ensure minimum motion blur (typically $10 \mu \mathrm{m}$ for a particle travelling at $2 \mathrm{~km} / \mathrm{s}$ ). Images are $1360 \times 1024$ pixels with equivalent size of $3.5 \mu \mathrm{m} /$ pixel. All velocity values mentioned next are derived from initial positions and four successive positions recorded at times 250, 500, 850 and $1100 \mathrm{~ns}$ after the laser shot (see Appendix). Error bars in these values, essentially due to uncertainties in determining the positions of the diffuse fronts in the pictures, are estimated to about $\pm 3 \%$. All measured velocities are found to be constant within experimental uncertainty, which is consistent with ejection in vacuum, over such relatively long times after shock breakout. 


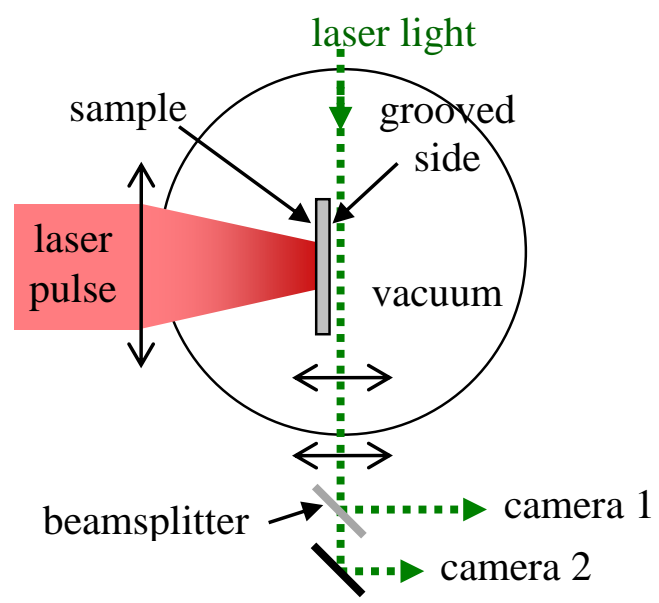

Fig. 3. Schematic of the experimental setup. Grooves in the sample free surface are parallel to the laser probe direction (vertical dotted line).

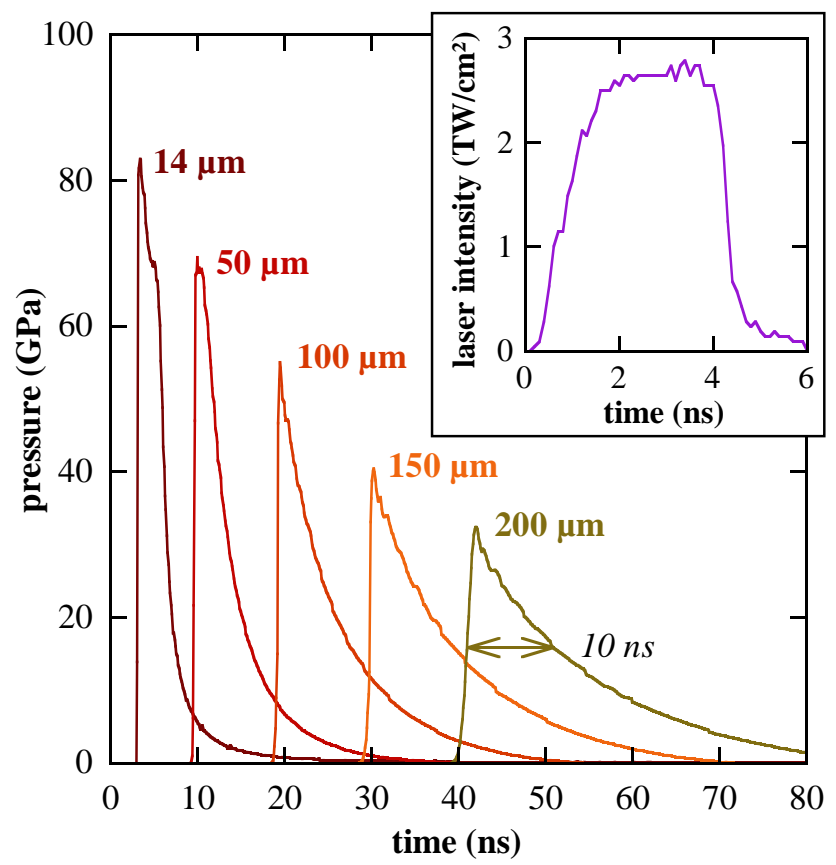

Fig. 4. One-dimensional simulation of laser shock loading for a $2.79 \mathrm{TW} / \mathrm{cm}^{2}$ laser intensity (inset), showing the evolution of the pressure pulse with increasing propagation distance from the irradiated surface (bold numbers). Shortly before shock breakout, $30 \mu \mathrm{m}$-deep beneath the grooved surface, peak pressure has decayed down to $32 \mathrm{GPa}$ and the pulse duration at half maximum is about $10 \mathrm{~ns}$. 


\section{Experimental results}

Fig. 5 shows three frames recorded behind the regular pattern of $18 \mu \mathrm{m}$-deep grooves $(k h=1)$, opposite to the centre of the loaded spot. A seemingly continuous cloud is observed to expand from this central pattern with a front velocity $V_{j(18)}=3.70 \mathrm{~km} / \mathrm{s}$. Outside this grooved zone, the smooth, planar surface is seen to break up into a slower, diffuse front which is typical of the cloud of droplets (sometimes called microspall) resulting from dynamic fragmentation of the liquid metal over a thick layer beneath the free surface, about $40 \mu \mathrm{m}$-thick in our loading conditions, where the reflected rarefaction wave interacts with the incident unloading wave [1719]. The measured velocities of this initially smooth free surface are $V_{F S}=1.88 \mathrm{~km} / \mathrm{s} \pm 50 \mathrm{~m} / \mathrm{s}$ in all shots reported in this paper. They are fully consistent with the $1 \mathrm{D}$ computations and $P_{S B}$ values mentioned above. The correct planarity near the central axis shortly after shock breakout and the overall symmetry assess to some extent the uniformity of the pressure load applied onto the irradiated spot. Similar images recorded behind the regular pattern of $10 \mu \mathrm{m}$-deep grooves $(k h=0.5)$ indicate a slower front velocity $V_{j(10)}=3.22 \mathrm{~km} / \mathrm{s}$. Such dependence on the perturbation geometry is consistent with all previous observations and theoretical expectations [5-14]. In particular, the velocity values are close to those measured in explosive-loaded tin with a slightly lower shock breakout pressure of $26.7 \mathrm{GPa}$, where free surface velocity was 1.85 $\mathrm{km} / \mathrm{s}$ and jet tip velocities were $2.99 \mathrm{~km} / \mathrm{s}$ and $3.45 \mathrm{~km} / \mathrm{s}$ for $k h=0.5$ and $k h=1$, respectively [6]. Such consistency is worth noting because both spatial and temporal scales are very different between both experiments. Thus, sample thickness $(230 \mu \mathrm{m})$ and diameter of the loaded zone $(3.1 \mathrm{~mm})$ were about $4 \mathrm{~mm}$ and several $\mathrm{cm}$, respectively, in Ref. [6]. Besides, in our laser shock experiments, the pressure pulse emerging at the grooved surface has a width at half maximum of about $10 \mathrm{~ns}$ (Fig. 4), whereas the duration of pressure application in explosive-driven shock loading, governed by the expansion of the detonation products, is typically of $\mu$ s-order, longer 
by two orders of magnitude. Finally, this longer duration of Taylor shockwave loading also implies a much slower decaying rate with propagation distance than in the laser-driven shock.

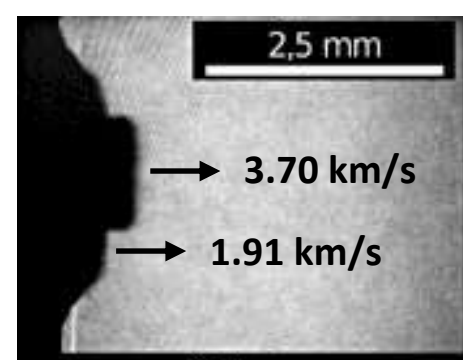

$250 \mathrm{~ns}$

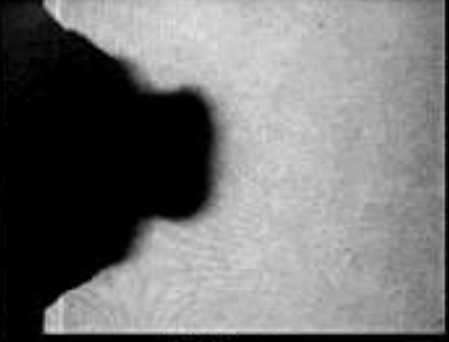

$500 \mathrm{~ns}$

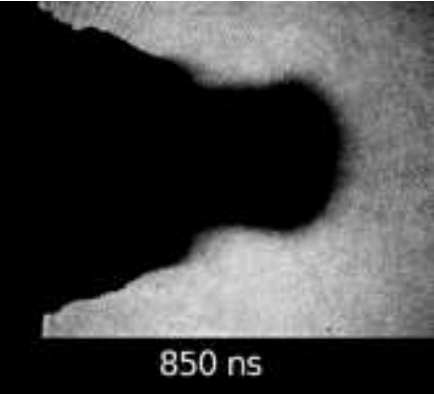

850 ns

Fig. 5. Shadowgraphs recorded behind the free surface of a $230 \mu$ m-thick tin sample subjected to a laser shock applied onto its left surface (not shown, hidden by the target holder). At the periphery of the loaded zone, a microspall is seen to expand at about $1.91 \mathrm{~km} / \mathrm{s}$ from the initially smooth free surface, while a cloud of faster particles is ejected from the central, periodic pattern of $18 \mu \mathrm{m}$-deep grooves, with a front velocity of $3.70 \mathrm{~km} / \mathrm{s}$.

Fig. 6 shows successive shadowgraphs recorded behind the three zone-patterns, with 10 $\mu \mathrm{m}$-deep grooves (top) and $18 \mu \mathrm{m}$-deep grooves (bottom). Distinct particle clouds expand from each grooved zone, with different tip velocities listed in the figure. Labels (A), (B), (C) refer to the same three zones as in Fig. 2b. Again, ejection velocity consistently increases with perturbation amplitude (i.e. groove depth). For a given shot, assuming homogeneous pressure loading in the central region as inferred from Fig. 5, the only difference between the three zones is the number of grooves, i.e. the boundary conditions at the edges of the zone. Unexpectedly, these edge conditions are shown to strongly affect peak ejection velocity, which is significantly lower for a single defect than for a periodic pattern, and which increases with groove number to approach the values $V_{j(10)}$ and $V_{j(18)}$ reported above for the regular patterns. 

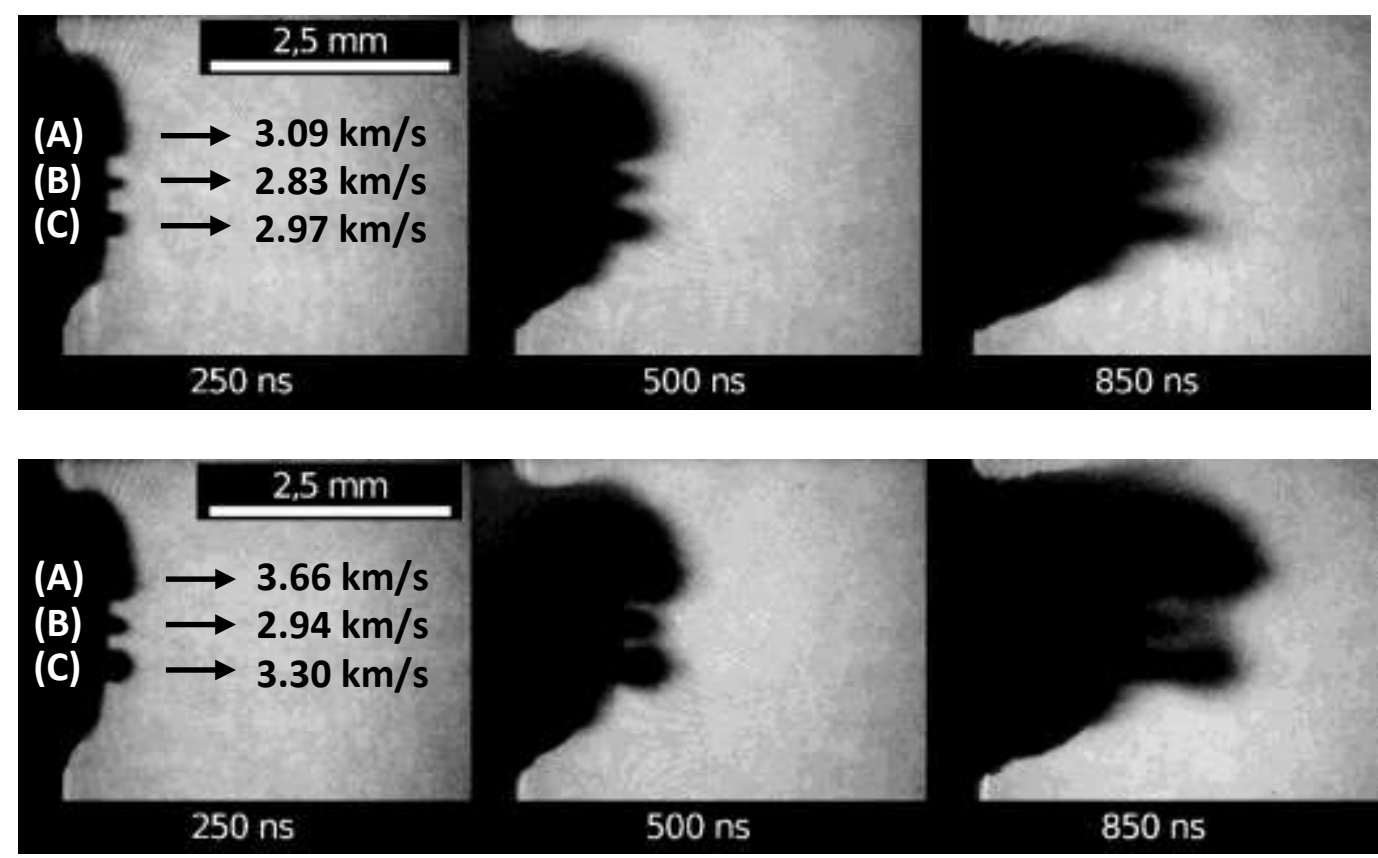

Fig. 6. Shadowgraphs recorded behind laser shock-loaded tin samples with a three zone-pattern engraved in their free surface, for a groove depth of $10 \mu \mathrm{m}$ (top) or $18 \mu \mathrm{m}$ (bottom).

\section{Discussion}

While ejecta production is known to depend on the loading conditions (i.e. shock breakout pressure and temporal profile of the drive) and on the geometry (wavelength and amplitude of surface perturbations), the influence of boundary conditions reported here had never been evidenced yet. In most phenomenological pictures of material ejection, including the widely used Richtmyer-Meshkov Instability (RMI) approach $[6,9,10]$, the spike raising from each concave segment (i.e. the bottom of the groove) is fed by matter flowing from the convex edges, forming bubbles on both sides. Meanwhile, rarefaction waves are induced upon breakout of the compression front at every free surface, either curved (groove edge) or planar (Fig. 7). Interactions between these waves cause tension, which will lead to fracture in a solid sample (as discussed and evidenced in Ref. [14]), or produce cavitation in a liquid metal [1719]. Such cavitation is expected to bound the amount of material to be excavated into each jet, so that this amount would be less in a periodic pattern (Fig. 7a) than in the case of a single 
groove (Fig. 7b). Assuming a same incoming kinetic energy in both cases, globally transferred to the ejecta, resulting velocities would then be higher in the periodic case (lower jetted mass) than behind a single groove, which qualitatively agrees with our observations. The apparent thickness of the central (single) jet in the pictures, about $200 \mu \mathrm{m}$, tends to confirm that ejecta probably include material flowing from well outside the initial groove (of much smaller width, about $50 \mu \mathrm{m}$ ). Interestingly, radiographs of ejection from explosive-loaded tin, both proton [6] and x-rays [10], often exhibit skew "cuts" growing from the edges of the grooved regions backward into the bulk of the sample, which look very similar to the final picture in Fig. $7 \mathrm{~b}$. Throughout the pulse reflection process, additional contribution of the incident unloading wave produces further cavitation and "micro-spall" [17-19], not represented in Fig. 7 for clarity. Finally, in the periodic case, neighbouring jets might interact with each other at later stages, which might limit transverse expansion and subsequent particle dispersion, and enhance axial velocity. Logically, the three-groove pattern seems to correspond to an intermediate regime between the single groove and the fully periodic case.
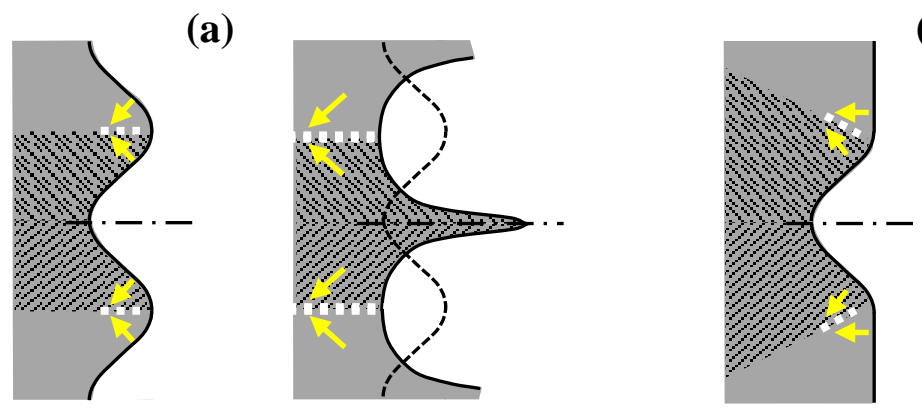

(b)

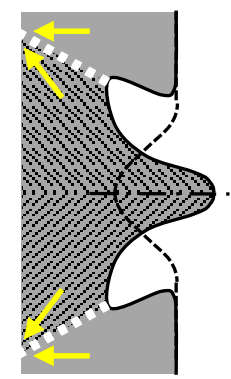

Fig. 7. Schematic picture of jetting upon shock breakout in the case of a periodic pattern (a) or a single groove (b). Arrows represent rarefaction waves propagating from free surfaces, either curved or flat. Their interaction produces cavitation (white dotted lines) which is expected to bound the mass source (hatched area) to be excavated into the jet. 


\section{Conclusion}

High power laser shock experiments on tin samples with various types of approximately sinusoidal grooves in their free surface have shown that peak ejection velocities depend not only on the groove depth and aspect ratio (which is consistent with jetting theories and former experiments) but also on the number of grooves (which was not anticipated). This dependence has been attributed to boundary effects at the groove edges, which have been qualitatively discussed in terms of cavitation caused by wave interactions, ejected mass, kinetic energy, and possible interactions between adjacent jets. Although edge effects on material ejection were evidenced under explosive loading in the past, their influence on jet tip velocity has not been clearly observed in such conditions yet. Thus, further work is still needed for a full characterization and a quantitative interpretation of these edge effects. Finally, those laser shock experiments involving periodic, approximately sinusoidal perturbations and shock-induced melting should be directly comparable with theoretical predictions based on the RMI approach.

\section{Acknowledgements}

The access to the LULI facility was allocated by the Institut Laser Plasma (ILP, FR \# 2707). We thank all the LULI staff for technical support, as well as Patrick Combis and Laurent Videau (CEA Arpajon) for providing the ESTHER code.

\section{Appendix : analysis of the shadowgraphs}

In the raw images recorded behind the sample surface at successive delay times (e.g. Fig. 5 and 6), the positions of all fronts (planar surface and jet tips) were determined in pixels, converted to $\mathrm{mm}$, then plotted versus time (Fig. 8), taking into account the transit time of $43 \mathrm{~ns}$, inferred from the simulations, between laser shot (camera trigger) and shock breakout (beginning of surface motion). The position of the planar surface outside the shocked zone, unchanged over 
the time of observation, was used as a fixed reference for both cameras. The velocities were derived from a linear fit (forced to pass through the origin) of the front positions (Fig. 8).

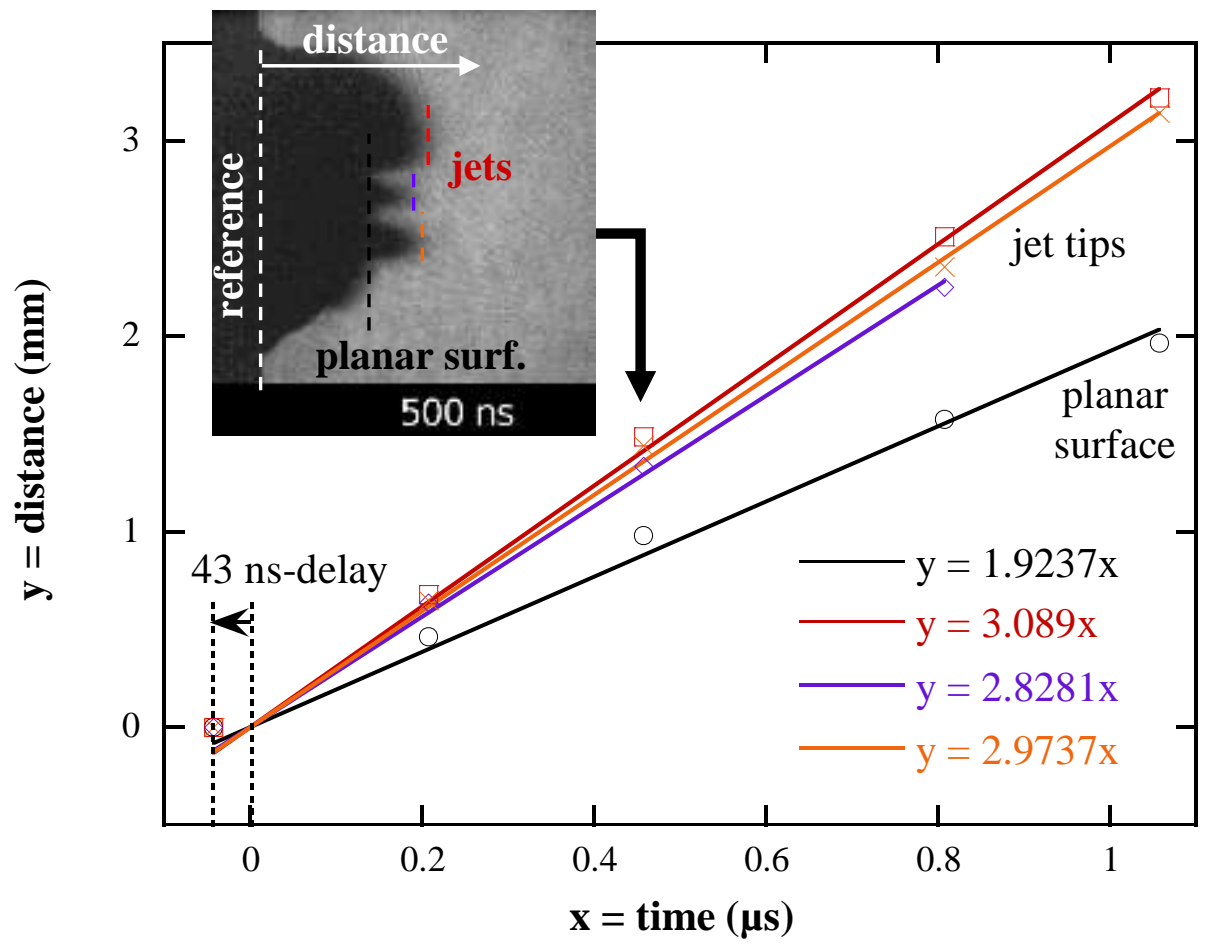

Fig. 8. Example of velocity determination from the shadowgraphs (shot shown in Fig. 6, top).

\section{References}

[1] J. R. Asay, L. P. Mix and F. Perry, Ejection of material from shocked surfaces, Appl. Phys. Lett. 29, 284, 1976.

[2] P. Andriot, P. Chapron and R. Olive, Ejection of material from shocked surfaces of tin, tantalum and lead-alloys, AIP Conf. Proc. 78, pp. 505-508, 1981.

[3] D.S. Sorenson, R.W. Minich, J.L. Romero, T.W. Tunnell and R.M. Malone, Ejecta particle size distributions for shock loaded Sn and Al metals, J. Appl. Phys. 92(10), 5830, 2002 
[4] M. B. Zellner, J. E. Hammerberg, R. S. Hixson, K. B. Morley, A. W. Obst, R. T. Olson, J. R. Payton, P. A. Rigg, W. T. Buttler, M. Grover, G. S. Macrum, G. D. Stevens, W. D. Turley, L. Veeser, A. J. Iverson and N. Routley, Effects of shock-breakout pressure on ejection of micron-scale material from shocked tin surfaces, J. Appl. Phys. 102, 013522, 2007.

[5] M.B. Zellner, W. Vogan McNeil, J.E. Hammerberg, R.S. Hixson, A.W. Obst, R.T. Olson, J.R. Payton, P.A. Rigg, N. Routley, G.D. Stevens, W.D. Turley, L. Veeser and W.T. Buttler, Probing the underlying physics of ejecta production from shocked Sn samples, J. Appl. Phys. 103, 123502, 2008.

[6] W.T. Buttler, D.M. Oro, D.L. Preston, K.O. Mikaelian, F.J. Cherne, R.S. Hixson, F.G. Mariam, C. Morris, J.B. Stone, G. Terrones and D. Tupa, Unstable Richtmyer-Meshkov growth of solid and liquid metals in vacuum, J. Fluid Mech. 703, pp. 60-84, 2012.

[7] O. Durand and L. Soulard, Large-scale molecular dynamics study of jet breakup and ejecta production from shock-loaded copper with a hybrid method, J. Appl. Phys. 111, 044901, 2012.

[8] J.L. Shao, P. Wang, A.M. He, S.Q. Duan and C.S. Qin, Atomistic simulations of shockinduced microjet from a grooved aluminium surface, J. Appl. Phys. 113, 153501, 2013.

[9] G. Dimonte, G. Terrones, F.J. Cherne and P. Ramaprabhu, Ejecta source model based on the nonlinear Richtmyer-Meshkov instability, J. Appl. Phys. 113, 024905, 2013.

[10] S.K. Monfared, D.M. Oro, M. Grover, J. E. Hammerberg, B.M. LaLone, C.L. Pack, M.M. Schauer, G.D. Stevens, J.B. Stone, W.D. Turley and W.T. Buttler, Experimental observations on the links between surface perturbation parameters and shock-induced mass ejection, J. Appl. Phys. 116, 063504, 2014.

[11] S.K. Monfared, W.T. Buttler, D.K. Frayer, M. Grover, B.M. LaLone, G.D. Stevens, J.B. Stone, W.D. Turley and M.M. Schauer, Ejected particle size measurement using Mie 
scattering in high explosive driven shockwave experiments, J. Appl. Phys. 117, 223105, 2015.

[12] O. Durand and L. Soulard, Mass-velocity and size-velocity distributions of ejecta cloud from shock-loaded tin surface using atomistic simulations, J. Appl. Phys. 117, 165903, 2015.

[13] F.J. Cherne, J.E. Hammerberg, M.J. Andrews, V. Karkhanis and P. Ramaprabhu, On shock driven jetting of liquid from non-sinusoidal surfaces into a vacuum, J. Appl. Phys. 118, 185901, 2015.

[14] T. de Rességuier, E. Lescoute, A. Sollier, G. Prudhomme, P. Mercier, Microjetting from grooved surfaces in metallic samples subjected to laser driven shocks, J. Appl. Phys. 115, 043525, 2014.

[15] J. F. Colombier, P. Combis, F. Bonneau, R. Le Harzic, and E. Audouard, Hydrodynamic simulations of metal ablation by femtosecond laser irradiation, Phys. Rev. B 71, 165406, 2005.

[16] C. Mabire and P.L. Hereil, Shock-induced polymorphic transition and melting of tin, AIP Conf. Proc. 505, pp. 93-96, 2000.

[17] T. de Rességuier, L. Signor, A. Dragon, M. Boustie, G. Roy, F. Llorca, Experimental investigation of liquid spall in laser shock-loaded tin, J. Appl. Phys. 101, 013506, 2007.

[18] T. de Rességuier, L. Signor, A. Dragon, M. Boustie, L. Berthe, On the dynamic fragmentation of laser shock-melted tin, Appl. Phys. Lett. 92, 131910, 2008.

[19] D. Loison, T. de Rességuier, A. Dragon, P. Mercier, J. Bénier, G. Deloison, E. Lescoute, A. Sollier, Skew Photonic Doppler Velocimetry to investigate the expansion of a cloud of droplets created by micro-spalling of laser shock-melted metal foils, J. Appl. Phys. 112, 113520, 2012. 